NBER WORKING PAPER SERIES

PRICING AND LOCATION OF PHYSICIAN
SERVICES IN MENTAL HEALTH

Richard G. Frank

Working Paper No. 1514

NATIONAL BUREAU OF ECONOMIC RESEARCH

1050 Massachusetts Avenue

Cambridge, MA 02138

December 1984

The research reported here is part of the NBER's research program in Health Economics. Any opinions expressed are those of the author and not those of the National Bureau of Economic Research. 


\title{
Pricing and Location of Physician \\ Services in Mental Health
}

\begin{abstract}
Puzzling results of a positive association between the number of physicians per capita and the level of fees for physician services have been reported in the 1 iterature. These results may be due to misspecification of econometric models and use of data aggregated across medical specialties. It is hypothesized that the unusual results would not persist with a carefully specified econometric model for a single medical specialty. A general model of pricing and location of physician's services is applied to the market for psychiatrist's services. The results imply that the market for psychiatrist's services operates in a manner consistent with the predictions of the competitive model.
\end{abstract}

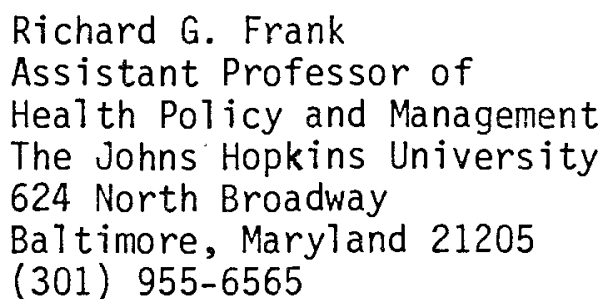

(301) 955-6565 


\section{Introduction}

Economic theory begins with the assumption that buyers will demand less of a good, and sellers will supply more, as price increases. Given these behavioral assumptions, if there is an increase in the number of sellers in the market, more will be supplied at any price, causing the market clearing price to fall. This leads economic theory to predict that, in the market for physician services, ceterus paribus, price will vary inversely with the number of physicians avaliable.

Econometric studies of physician pricing and location decisions, however, have repeatedly shown that a higher physician-to-population ratio is associated with higher, rather than lower, fees. The results of such studies have led economists to abandon traditional assumptions about the manner in which markets for physicians' services function. It has in fact been posited that physicians may be able to create their own demand or that they price in such a way as to maintain a target level of income. In the light of such information, many policymakers have begun to rethink the "wisdom" of increasing the number of physicians as a policy for decreasing the cost of medical care. Several government officials have even recommended that the number of places in medical schools be limited in order to lower fees for physician services.

In the research discussed in this paper, we examined the pricing and location of private psychiatric services in a market model in which the supply of providers was allowed to adjust slowly to changes in demand. One of the primary advantages of selecting psychiatry is the relatively homogeneous nature of mental health services. In addition, psychiatrists are one of the few specialists subject to meaningful competition from non-medical providers.

\section{Methodological Issues in Studies of Physician Fee Setting}

The studies of Newhouse (1980) and Feldstein (1970) were the first serious attempts to test models of physician fee determination empirically. In both it 
was found that increasing the physician-to-population ratio would result in increased fee levels, ceterus paribus. These studies were critized on empirical and theoretical grounds, and their results led to one of the most heated controversies in health economics. However, subsequent investigations obtained similar findings (see Fuchs and Kramer 1972, Dyckman 1978 and Fuchs 1978).

Over the past ten years, analysis of the theoretical models proposed to reconcile the empirical findings of these studies with predictions of economic theory led to questions about the existing methods of modeling fee determinasion in the physicians' services market. Most empirical studies of physician fees are based on market models in which short-run equilibrium is presumed to exist. The predictions of the neo-classical model are then tested according to how well parameter estimates coincide with traditional assumptions. A number of studies have attempted such tests. Three major points regarding estimation of such models have emerged from the literature.

First, data should be disaggregated by medical specialty. 2 Data aggregated across specialties may indicate a relationship between the average fee level and the physician-to-population ratio that is spurious. Differences in average fees between locations when aggregated across specialties may not result from differences in the model's explanatory variables but rather from the specialty mix. 3

In addition, it is likely that there exist interrelationships between medical specialties. While it is probable that a number of specialties compete (i.e., for patients), it may be that some specialties act as complements to others. This also may produce a spurious correlation between the average fee and the physician-to-population ratio. For instance, increasing the number of general practitioners may lead to lower fees for the services of general 
practitioners but also to increased demand for the services of internists, which will exert upward pressure on their fees.

Aggregation across specialties may lead to difficulties in the interpretation of empirical results also because input time of the physician varies between specialties. For example, a visit to the office of a general practitioner for a routine physical examination often involves rather extensive use of a nurse's time and relatively little use of physician time. A visit to the office of a psychiatrist for psychotherapy involves, almost exclusively psychiatrist time. Fee or quantity variables based upon aggregate data will vary considerably, depending on the procedure mix in each locality.

A second empirical issue which emerges from the literature is that the physician-to-population ratio may be endogenous to the short-run fee-setting model, and the treatment of the physician stock as exogenous may lead to biased and inconsistent parameter estimates. Difficulties associated with fully specifying the demand equation in the physician services market may lead to specification error. Thus, the inclusion of a long-run location model within a model of physician pricing may minimize the chance that biased parameter estimates of the relationship will occur between the physician-to-population ratio and the level of fees.

Problems of misspecification in constructing empirical tests in models of physician fee setting have plagued earlier studies. Reinhardt (1978) takes a dim view of criticism of studies which have obtained results inconsistent with traditional predictions of the competitive model due to misspecification. He suggests that any study is vulnerable to such accusations, and such criticism can always be levied at an attempt to reject the competitive model's predictions in the physician services market. While there is considerable truth in Reinhardt's position, the concerns with misspecification are not limited to 
trivial omissions of obscure variables. 4 To a large extent, specification problems may be the very basis for puzzling empirical results.

These methodological pitfalls (aggregated data, treatment of physician stock as exogenous, and specification error) make it difficult to interpret the empirical results on physician fee determination reported in the literature. Differentiating between the competitive model and alternatives such as the model of physician-induced demand is difficult on theoretical grounds. Reinhardt (1978) and Sloan \& Feldman (1978) point out that both physicianinduced-demand and competitive models can yield predictions that are consistent with all empirical estimates of the relation between the physician-to-population ratio and the fee level. They show, however, that a negative relationship suggests that competitive forces are dominant. In neither case can one model be unambiguously rejected. Even a limited test of the competitive model requires that a carefully specified model of physician fees be applied to a single medical specialty.

\section{A Model of Pricing and Location of Psychiatrists' Services}

No definitive test on the nature of market structures for the physician services market has yet been developed. In addition, empirical results from econometric models do not clearly support one formulation of market structure over others. In this study of the market for psychiatrist's services, we began by using the competitive model as the starting point. We assumed that the individual psychiatrist is a price taker. From this assumption, we derived a market supply function

(1) $Q^{S}=Q^{S}\left(P_{0}, P S, X\right)$

where Qs is the quantity, of services supplied to the market Po is the psychiatrists own fee for a unit of service $X$ is a vector of variables representing the psychiatrist's cost function PS is the psychiatrist-to-population ratio 
The specific shape of the supply function given in equation (1) is an empirical question. Feldstein's (1970) finding that the supply curve had a negative price elasticity might mean that the supply curve for physician services with respect to fees is backward bending. We do not rule out this possibility.

The demand function is assumed to be a traditional negatively inclined function with respect to fee. It is important to recognize explicitly the existence of other medical and nonmedical providers of psychotherapy and the effect of their actions on the market for psychiatrists' services; for example, McGuire (1980) points out that the effect of psychologists on the market for psychiatrists' services may be of particular importance. Thus, we enter the cross-price effects of other providers of psychotherapy into our demand equation, allowing for a test of some of the less obvious relations anong providers where our theory does not make clear predictions. 5 It has been hypothesized, for example, that the cross-price elasticity of an increase in psychologists' fees on the demand for psychiatrists' services will be positive, i.e., that psychiatrists and psychologists are substitutes in demand. The extent to which general practitioners and internists are substitutes for psychiatrists in that they provide similar services or complements, in that they provide referrals, is not clear. 6

Another important issue in the demand function specification is the manner in which insurance coverage is treated. The literature typically assumes that insurance simply shifts the demand curve in some fashion, and that a standard short-run supply curve exists. Thus prices respond to the shift in demand in such a way as to establish a new short-run equilibrium. Representing insurance in terms of the total value of health insurance benefits paid or the number individuals with some insurance coverage in a particular geographic area describes only one dimension of the effect of insurance coverage. It is 
important to establish how much coverage exists and for which medical procedures.

Coverage for mental disorders under major medical plans may be characterized as significantly less extensive than coverage for physical ailments. 7 Thus, specification of the effect of insurance on the demand for psychiatric services must be more complex than what can be measured by merely including a single-demand shift variable. A number of state legislatures have responded to the paucity of insurance coverage for mental disorders by requiring insurance companies to offer mental health coverage as part of their basic benefit packages (McGuire and Montgomery 1982); the guidelines set up by the states vary widely in the breadth of coverage they require insurers to offer. Since this study focuses on the market for psychiatrists' services delivered in their offices, a variable describing whether each state has mandated a minimum level of outpatient mental health coverage of $\$ 500$ will be included in our demand function specification. In this manner we will be able to estimate the effect of general, as well as specifically psychiatric, insurance on the demand for psychiatrists' services. A significant limitation of this specification is that the marginal price of services to the population is not measured directly. Instead, we use aggregate measures of the amount of coverage existing within the population. Newhouse, Phelps and Marquis (1980) discuss this problem in considerable detail. 8 With these specific issues in mind, then, the demand function can be expressed as follows:

(2) $Q^{d}=Q^{d}\left(P_{0}, P_{m}, P_{n m}, Y, I, K\right)$

where $\mathrm{Qd}^{\mathrm{d}}=$ The market demand for psychiatrists' services

$P_{0}=$ Fees for psychiatrists' services

$P_{m} \quad=$ Fees of medical providers

$P_{n m}=$ Fees for nonmedical providers 


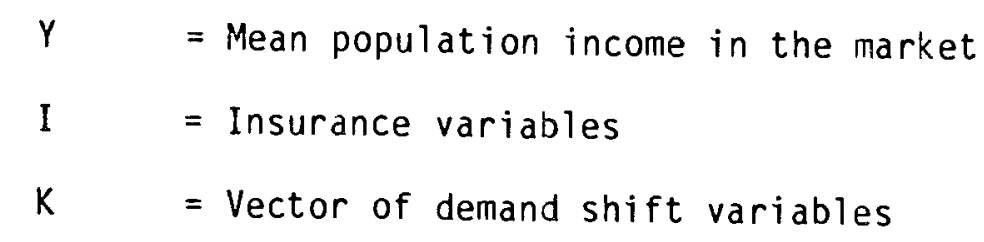

The physician-induced demand model and the target income model raise serious challenges to the standard neoclassical model presented thus far. Because the ability to create demand is unobservable, as is the target income, most empirical tests of these models are indirect.9 The test used most often in the past has been the estimation of the coefficient corresponding to the psychiatrist-to-population ratio in the supply function. If the supply and demand curves have their usual shapes, then a positive coefficient will be consistent with the traditional model as well as with the inducement model; the result will reject the prediction of the traditional model if the coefficient is negative. In this study we test the competitive model by inclusion of the psychiatrist-to-population ratio.

A second test of competitive forces (used in this study) involves the location decisions of psychiatrists. If the ability to create demand can significantly insulate a psychiatrist from market forces, then one would expect little responsiveness on the part of psychiatrists to distribute themselves geographically, according to demand. If, on the other hand, psychiatrists do respond to market forces, one might expect the opposite. The significance of specifying a model of physician location as part of the price determination model extends beyond statistical considerations: embedding a location model offers a theoretically derived test of competing models of physician behavior. 10

Since psychiatrists' fees, quantity of services supplied, and the psychiatrist stock may be jointly determined, a model of psychiatrist location in this study is integrated with a short-run market model of psychiatrist behavior. The stock of psychiatrists may adjust slowly over time; this possibility is explicitly recognized and specified as part of the econometric model. 
Psychiatrists are assumed to be utility maximizers and to locate in areas that offer the greatest combination of personal and professional advantages. The individual psychiatrist maximizes a utility function which has income, workload, and the quality of life as arguments. If there is free entry into local markets, the long-run equilibrium would imply equal levels of utility across all locations, i.e., each location will offer an entering psychiatrist a combination of monetary and nonmonetary advantages that are equivalent.

In long-run equilibrium, the stock of psychiatrists may then be expressed in the following fashion:

$$
\text { (3) } P S^{i}=f(P, Z)
$$

where PS ${ }^{i}$ - is the psychiatrist stock at the $i^{\text {th }}$ location

$p$ - is the fee for 1 unit of psychiatrists' services

$Z$ - is a vector of locational characteristics

The stock of psychiatrists may not adjust immediately. Psychiatrists in private practice sell their services directly to the public and must therefore invest considerable resources in establishing goodwill. Therefore, finding new patients and gaining their trust and confidence in a new market may involve significant costs. In addition, there exist financial impediments to mobility in the form of sizable investments in establishing an office; these costs must be contrasted with the advantages offered at other locations. The decision rule for the utility-maximizing psychiatrist is that he or she will move if the utility offered by other locations is greater than the costs of moving, ceterus paribus, and migration will occur until no net gains from migration can be realized. Under these circumstances, the rate of adjustment of the psychiatrist stock depends on the cost of moving relative to the benefits arising from disequilibrium. The rate of adjustment to disequilibrium in the market can be described by a lagged adjustment model as described by Griliches (1967): 
(4) $P S_{t}^{i}-P S_{t-1}^{i}=\lambda\left(P S^{i *}-P S_{t-1}^{i}\right)$

where $\lambda$ is the coefficient of adjustment

PSi is the equilibrium stock of psychiatrists

PSi is the actual stock of psychiatrists

Equation (4) describes the rate of adjustment in one time period of the actual level of the psychiatrist stock to the desired or equilibrium level. By substituting equation (3) into equation (4), the stock of psychiatrists can be expressed in a form that can be incorporated into an econometric model. The location equation will be of the form:

(5) $P S_{t}^{i}=\lambda(f(P, Z))+(1-\lambda) P S_{t=1}^{i}$

Estimation of will allow for the empirical identification of the rate of adjustment of the psychiatrist stock to long-run disequilibrium. An estimate of $\lambda$ close to zero indicates little responsiveness to market forces, which would provide support for the inducement model, whereas an estimate substantially greater than zero would indicate responsiveness to market pressures and would be consistent with the competitive model. Thus far, a 3-equation model of the psychiatrists' services market has been developed, based on the assumptions of the competitive model (equations 1,2 , and 5 ).

\section{Specification and Estimation}

The general functional form of the 3-equation model is a hybrid of the log-linear and linear. Monetary variables such as prices, incomes, and insurance benefits are specified in the usual log linear form, while variables describing the socio-demographic characteristics are entered in linear form. In the present study, the structural model was estimated using pooled time series and cross-section data. The data on 50 states for a number of years were pooled to make up the data set. Combining time series and cross-section data made estimation more difficult than with either time-series or crosssection data individually. The least square dummy variables (LSDV) approach to estimation was used (see Mundlak 1978) in this study because there is reason to 
believe that there may be non-zero correlations between the time-series and cross-section effects and the independent variables. To retain degrees of freedom, the model was estimated using cross-sectional dummy variables representing geographic regions of the country rather than individual states. An $F$ test was used to compare estimates using regional dummies, to those obtained from using state dummy variables. The model was estimated by three stage least squares (3SLS).

Data and Variable Definitions

The data used to estimate the model of the market for psychiatrists' services are a cross section of time series of the 50 states of the United States. Data from several sources were merged in order to assemble this data set. Variables included in the study and the sources from which they were collected are reported in Table 1. The data set, which consisted of a time series of cross sections (states) for the years 1970 to 1978 was subdivided into two smaller data sets because several critical variables were unavailable for some years. Data on psychiatrists' fees were available for the years 1970 , $1971,1973,1977$, and 1978. Allowing for the construction of two data sets. One was based on five years of data which contained 250 cases; the other was based on three years of data, which resulted in a data set of 150 cases. Mean and standard deviations for selected variables are present in Table 2. A detailed description of the data can be obtained from the author.

Two versions of the structural model described above are estimated below. Model I is estimated for three years of data across 50 states. The fee data for each of these three years is based on observations from within each state, aggregated to obtain a state-wide average fee. Fee data for these years are also available on visits to the office of general practitioners and internists. Thus data allowed for estimation of explicitly cross-price elasticities between medical providers. 
Model II is based on five years of data across 50 states. Two years (1970 and 1971) of fee data are based on averages for the geographic region in which the state is located. Fee data for other medical providers are not available. Therefore, a variable representing the number of non-psychiatrist physicians per capita (MDPOP) is entered into the demand equation in place of the fees for internists and general practitioners. 11

\section{Demand Equation Estimates}

The estimates of Structural Models I and II are reported in Table 3.12 Since the endogenous variables FEE and PLVIS, as well as all monetary-independent variables, are in $\log$ form, estimates of those parameters can be interpreted as elasticities.

The estimated own price elasticities of demand (LFEE) are both negative and significantly different from zero. The values of the estimated elasticities for the two models differ substantially (according to a t-test). 13 Model I $(-0.918)$, and Model II reported an estimate of $(-2.199)$. These estimates are significantly different from one another using a t test. A previous estimate (McGuire 1981) of the price elasticity of demand for psychiatrists' services, based on survey data using individuals as the unit of observation, obtained estimates for the effects on the quantity demanded for changes in coinsurance. McGuire's "conservative" estimate of the total effect on demand of a fall in the marginal fee paid by the consumer was $(-1.00)$, closer to our Model I estimate. Our estimates may differ, due to the fact that the variables which represent the influence of other providers are not equally measured in the two models.

The cross-price elasticities of demand in Model I (LPIN and LGP) were estimated to be $(-0.665)$ and $(0.485)$, respectively. The estimate for the cross-price elasticity of demand for the price of internists' services (LPIN) was significantly different from zero at the $(0.10)$ level. The negative sign 
indicating that internists are complements in demands means that as fees of internists increase, ceterus paribus, the demand for psychiatrists' services will decline. Such a finding suggests that internists may be a source of referrals to psychiatrists. The magnitude of the coefficient $(-0.665)$ implies that a 1 percent increase in fees of internists will lead to a .6 of one percent decrease in the demand for psychiatrists' services, considerably larger than what was expected: most estimates of own price elasticities for primary care physicians have been about 0.30 . This may, in part, reflect the imprecision of the estimates. The sign of the coefficient, however, provides evidence of complementarity.

The coefficient representing the cross-price elasticity of demand for psychiatrists' services with respect to general practitioners was estimated to be (0.485). This cross-price elasticity was only significant at the $(0.10)$ level. The positive coefficient would indicate that the two services are substitutes; a 1 percent increase in the fees of general practitioners will lead to a .485 of 1 percent increase in the quantity of psychiatrists' services demanded. Given the rather large volume of psychiatric patients seen by general practitioners (GP's), it is not surprising to find that a considerable amount of substitution may occur between the services of GP's and psychiatrists. ${ }^{14}$ Again, the magnitude of the coefficient is larger than expected. The size of standard error indicates a lack of precision in the estimate.

The variable REMB takes on a value of 1 for states that have enacted legislation requiring direct recognition of psychologists as independent health care providers by third party payors, and zero for states that have not. This variable represents the cross-price effect of psychologists' services on the demand for psychiatrists' services. The estimated coefficient for REMB was $(-0.138)$ for Model I and $(-0.168)$ for Model II. Both these estimates were significant at the 0.10 level; once again, the rather low level of significance 
means that the interpretations of the coefficients must be made with a good deal of caution. Both coefficients are negative, which can be interpreted as suggesting that psychologists' services are substitutes in demand for those of psychiatrists. The estimated coefficient for REMB indicates the difference in the number of visits made to psychiatrists between states that have differing policies vis a vis reimbursement of psychologists. Since the dependent variable in the demand equation is measured as the log visits to psychiatrists per capita, the estimated coefficients of -0.138 and -0.168 imply that states that require direct recognition of psychologists as health care providers by third party payors have between 14 and 16.8 percent fewer visits per capita to psychiatrists, all things equal, than states that do not require direct recognition. These estimates provide some evidence that psychiatrists' and psychologists' services are important substitutes in demand.

The estimated coefficient for LINS was 0.057 for Model $I$ and 0.115 for Model II; neither estimate was significantly different from zero. The estinated coefficient of the variable OUT5 was estimated to be 0.222 for Model I and 0.119 for Model II; both were significant at the 0.10 level. These estimates imply that in states where insurance plans must offer 500 dollars of outpatient mental health benefits, demand for psychiatrists' services will be significantly greater than in states without such mandates (McGuire and Montgomery 1982). Thus, it is likely that expansion of outpatient coverage for mental disorders would expand the demand for psychiatrists' services substantially. OUT5 and the own price elasticity of demand both measure aspects of the responsiveness of consumers to the out-of-pocket price for mental health service. OUT5 also measures the extent of outpatient insurance benefits for the treatment of mental disorders, and LFEE the gross price of psychiatrists' services. It was expected that the coefficient estimates for the two variables 
would be consistent with each other; i.e., when fees for psychiatric services are lowered, consumers are very responsive in their consumption of more psychiatric services. This expectation was borne out by our results.

\section{Supply Equation Results}

The own price elasticity of supply (LFEE) was estimated to be 0.127 in Model I and 0.233 in Model II. Model I's estimate was significant at the (0.10) level and Model II's estimates at the (0.05) level. The supply function is rather inelastic in the short-run, which may be expected if psychiatrists relocated slowly. The results are consistent with the fact that psychiatry is time-intensive for the psychiatrist, and since the basic unit of service is the 50-minute psychotherapy visit, the possibilities for expanding output by input substitution are quite limited.

Perhaps the most controversial findings in the literature have focused on the reaction of the market to an increase in the stock of physicians (psychiatrists, in this case). The estimated coefficients for the variable LPSP in the supply equations were 0.962 for Model I and 0.964 for Model II, and both were significantly different from zero at the 0.05 level. This result means that increasing the stock of psychiatrists in a state by one percent will increase the quantity of services by about .96 of one percent 15 and is consistent with the predictions of the competitive model. That is, an increase in the number of providers per capita should shift the supply curve to the right, thereby increasing the quantity supplied at each fee level. These estimates are stable across the two models, and the standard errors are small. When the coefficient LPSP is included in a partial reduced form equation with LFEE as the left-hand side variable, the estimated coefficient is negative. Moreover, the simple correlation between LFEE and LPSP was 0.113 , suggesting that our approach to model specification removes the observed positive correlation 
between physician fees and the physician stock. These results indicate behavior in the market for psychiatrists' services that is in line with the competitive model.

\section{Psychiatrist Stock Equation Results}

The stock equation, unlike the demand equation, has the same specification in both models. The use of proxy variables was not necessary for the larger data set. Therefore, the increased sample size made for statistically more robust estimates. Table 4 reports the long-run elasticities of selected variables from the location equation. 16

Perhaps the most surprising result from the psychiatrist stock equation is the contradictory and statistically insignificant results associated with the fee variable indicating market conditions. Coefficients were estimated to be -0.625 for Model I and 0.163 for Model II. In neither case were the estimates significantly different from zero. As was mentioned earlier, the longer time frame of Model II makes us slightly more confident of those results. The estimates indicate that a 10 percent increase in fee would lead to ejther a 6.2 percent decrease in the psychiatrist stock or a 1.7 percent increase. The negative sign on Model I's coefficient is rather implausible; thus, we are more inclined to accept Model II's estimate. Both results do suggest that price as measured by LFEE is not an important determinant of the current distribution of the stock of psychiatrists across locations.

The variable LYP, which represents the per capita level of income in each state, was found to be significantly related to the stock of psychiatrists across states. The estimated long-run elasticity for LYP was 1.18 for Model I and 0.850 for Model II. Model II's elasticity was derived from an estimate that was significant at the 0.05 level; Model I's estimate was significant at the 0.05 level. Thus an increase in per-capita income of 10 percent will increase the stock of psychiatrists by between 8.5 and 10.1 percent. These 
results are similar to those reported by Benham et al. (1968), who concluded that physicians tend to locate in high income areas because of the greater purchasing power in those markets. This finding to some extent contrasts with the LFEE results. The LFEE variables should summarize the supply and demand conditions of the market, and therefore differences in purchasing power should be reflected in market price. An alternative interpretation is that the income variable LYP represents some aspects of the quality of life in a state, e.g., the type of people one will have as neighbors and the distractions that will be present for the high-income professional. This interpretation of the LYP coefficient runs counter to the simple competitive model and says, in essence, that psychiatrists will choose location on the basis of non-economic factors.

The estimated coefficient on the psychiatrist-to-population ratio lagged one period can be used to calculate the rate of adjustment in the psychiatrist stock over time. The estimated coefficients were 0.792 for Model I and 0.598 for Model II. Both estimates were significantly different from zero at the 0.05 level. The adjustment coefficient can be expressed in terms of the estimated coefficient in the following manner:

$$
\lambda=1-\beta
$$

Our estimate for $\lambda$ in Model $I$ is 0.196 and for Model II, 0.402. This means that from $20-40 \%$ of the gap between the long-run equilibrium level and the actual level of the psychiatrist stock will be filled in any single year. The stock of psychiatrists, therefore, appears to adjust rather slowly.

\section{Conclusions}

The most important conclusion of this study is that the market for psychiatrists' services appears to respond to the forces of competition to an extent greater than previously thought. Competitive pressures appear to effect 
the demand and supply functions in ways that are consistent with the competi tive model. In particular, increasing the stock of psychiatrists shifts the supply function rightward along a downward sloping demand function, which leads to lower fees for the services of psychiatrists. This finding takes on particular significance when it is viewed in the context of comments by federal policy makers who advocate decreasing the stock of physicians as a means of lowering fees.

Since the structural model coefficient estimates of the physician-topopulation ratio in supply and reduced-form equations do not serve to differentiate unambiguously the competitive model from competing models, one must rely upon indirect tests. The indirect test is based on the responsiveness of the stock of psychiatrists' to market conditions (our $\lambda$ coefficient). Evidence from the indirect tests performed in our analysis suggests that psychiatrists do react to long-run spatial disequilibrium, albeit slowly. That is, in any one year, psychiatrists move so as to fill approximately 20 to 40 percent of the gap between the desired level of the long-run equilibrium stock of psychiatrists and the actual stock. Thus, psychiatrists are not insulated from market forces; instead, they may be utility maximizers facing significant moving costs, which makes the adjustment occur slowly.

The estimates of the effects of other medical specialities on the demand for psychiatrists' services illustrates the importance of disaggregating data regarding physician visits and fees by specialty. The existence of both complementary and substitute relationships between psychiatrists, internists, and general practitioners indicates that puzzling results reported by studies of physician pricing using aggregate data may have, at least in part, been the result of interrelationships among specialities. 
We recognize that while there are significant differences between the circumstances facing the specialty of psychiatry and other medical specialties, there are important similarities that make our findings suggestive of approaches by which to study and interpret of pricing and location of physician services. We conclude that the controversial results reported in the literature are likely to be the result of specification error and bias resulting from aggregation of fee data across specialties. Our results provide evidence that the market for physician services may very well conform to the standards of the competitive model. 


\section{ENDNOTES}

1. Assistant Professor of Health Policy and Management, The Johns Hopkins University: The author appreciates valuable comments from Thomas McGuire, Barbara Good, 0ldrych Kyn, Robert Wolf, W.P. Welch, John Chant, Mona Hersch and an anonymous referee and gratefully acknowledges financial support from the Pharmaceutical Manufacturers Association and the Foundation's Fund for Research in Psychiatry. This paper is adapted from the author's unpublished Ph.D. dissertation (1981).

2. Studies that have used aggregate data to study fee setting in the physician services market include: Feldstein (1970), Dyckman (1978), and Pauly and Satterthwaite (1980).

3. For example, perhaps two locations have exactly the same values for all explanatory variables except that the physician-to-population ratio is greater in location 1. Location 1 also has a mix of specialists in which radiologists are overrepresented relative to location 2 . One might reasonably expect to find a positive relation between the physician-topopulation ratioand the level of fees. This would occur, but not because physicians price to maintain a target income or because they possess the ability to induce demand for their own services. Radiologists offer more costly services than do other physicians and that would weigh the results.

4. Evans (1974), for instance, omits the entire demand side in his model of physician billing. Dyckman (1978) omits variables representing geographic regions of the United States and obtains "statistically significant" results that are consistent with the model of physician-induced demand but which reject the neoclassical predictions. That is, he estimates the partial correlation between fees and the physician-to-population ratio to be positive in a reduced-form price equation. However, when regional dummy variables are included in his estimated model, the statistical 
significance of his results disappears and the estimated coefficient shrinks by 33 percent.

5. One indicator of the extent of competition in a market is the number of providers offering services that are substitutes for the service in question. The market for psychiatric services is particularly interesting 
in this respect. The number of visits to physician offices for psychotherapy has been estimated for a number of medical specialties by the National Center for Health Statistics (1980). That office reports that general practitioners had over 6.2 million visits for psychotherapy in 1977, while internists had 3.6 million. Psychiatrists in 1977 had 15.9 million visits for psychotherapy. These figures give the impression that there are considerable numbers of similar services available from alternate providers who are physicians.

6. Medical specialists may be complements for each other. If one specialty, e.g., internists, often diagnoses conditions that require surgery and then refers patients for the appropriate treatment, internists and surgeons may be complements. In that case, an increase in the price of diagnostic visits to an internist would decrease the number of patients making visits to internists; the number of patients referred by internists to surgeons might also decline. This would satisfy the conditions necessary for the two specialists' services to be considered gross complements.

7. It was estimated by Reed (1975) that approximately 43 percent of the population had coverage for some type of physician office visits; 37 percent of the population had some coverage for outpatient mental health care. More important than the raw total of how many people had coverage for each class of disorders is the nature of the coverage offered each group. Reed also reports that in only 47 of 148 insurance plans that he surveyed was there greater or equal coverage for mental disorders than for physical illness treated in an outpatient setting.

8. Relying upon the mandated mental health benefits dummy variable (OUT5) and the per-capita coverage by health insurance (LINS) makes obtaining precise estimates of the effect of insurance difficult. Newhouse, Phelps, and Marquis (1980) discuss the use of a dummy variable to indicate whether or 
not an individual has insurance coverage. They point out the possibility of specification errors arising from this approach. In this study our market area is the state; this forces us to aggregate across individuals with different coverage. We will be able to estimate effects of policy changes such as adoption of a mandate which in the case of mental health insurance is likely to dominate other forms of coverage in most states. For changes that effect the level of insurance benefits in a state, we must implicitly assume that the individual consumer responses are uni form.

9. For example, the empirical studies of Dyckman (1978) and Fuchs (1978) estimate the coefficient representing the relationship between the physician-to-population ratio and the fee level. Reinhardt has pointed out that any empirical result on this relationship is consistent with the inducement model, while only a negative parameter estimate is consistent with the traditional model. This makes rejection of the target income model and the inducement model difficult. However, it is possible to test the importance of the ability to induce demand in insulating the psychiatrist from market forces.

10. Indirect tests are necessary because, as Sloan and Feldman (1978) point out, a positive relationship between quantity demanded and the physicianto-population ratio is consistent with a number of theoretical formulations. Increased physician density may lower time prices (e.g., travel and waiting time); this can result in a positive relation between demand and density. Thus, the common practice of including physician density in the demand equation is ad hoc and leads to ambiguous results.

11. Eight regional dummy variable are included to control for unmeasured cross-section effects in the disturbance term. Regions are used instead of states, largely in order to gain degree of freedom for our estimates. 
However, we tested the homogeneity of the slope coefficients between the two dummy variable specification (states and regions) and found that no significant difference existed. Table 2 presents variable mean and standard deviations. Using the $F$ test for differential sloped vectors (Johnston 1972, p. 199), we obtained a coefficient of F78, $108=1.04$. Therefore, we conclude that our estimates will not be altered by the use of the regional dummies.

12. Several reduced form price equations were estimated and obtained negative partial correlations between the psychiatrist-to-population ratio and fee. These are available from the author.

12. $t=(.05) . \quad t=\hat{\beta}_{1}-\hat{\beta}_{2}$

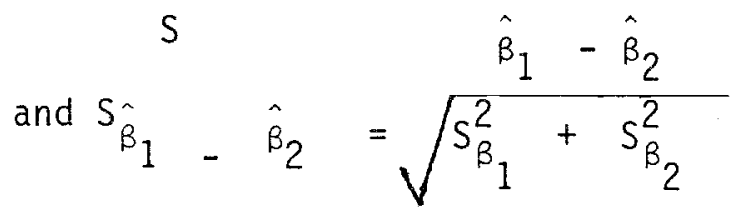

13. NAMCS reports the 4.4 million psychiatric visits were seen by the GP's.

14. Using a standard $t$ test and testing for a difference between 0.96 and 1.00 , we could not reject the null hypothesis that BLPSP $=1$, which is what strict competitive theorists would predict.

15. This result of $B$ LPSP $=1$ is not entirely surprising, given the manner in which the LPVIS variable is measured. The two equation partial reduced form (LPSP endogenous) is available from the author.

16. Since our estimating equation is $\mathrm{PS}_{t}^{i}=\lambda(f(P, Z))+(1-\lambda) P S_{t-1}^{i}$ the variable $P$ in those in the vector $Z$ must be adjusted by $\lambda$ in order to obtain the long run elasticities. 
Table 1

Variable Definitions

\begin{tabular}{|c|c|c|}
\hline Variable & Definition & Source \\
\hline POP & Population of state (000's) & Statistic Abstract (SAB) \\
\hline CP I & $\begin{array}{l}\text { Consumer price index by } \\
\text { geographic region }\end{array}$ & $\begin{array}{l}\text { Bureau of Labor } \\
\text { Statistics (BLS) }\end{array}$ \\
\hline PSPOP & $\begin{array}{l}\text { Number psychiatrists in } \\
\text { patient care per } 1000 \text { popula- } \\
\text { tion }\end{array}$ & $\begin{array}{l}\text { American Medical } \\
\text { Association (AMA) }\end{array}$ \\
\hline LPSP & In (PSPOP) & \\
\hline OPSY & $\begin{array}{l}\text { Number office based psychi- } \\
\text { atrists in each state }\end{array}$ & AMA \\
\hline HRWK & $\begin{array}{l}\text { Average number hours spent in } \\
\text { private practice by psychiatrists }\end{array}$ & $\begin{array}{l}\text { AMA/American Psycia- } \\
\text { tric Association (APA) }\end{array}$ \\
\hline PVISIT & $\begin{array}{l}\text { Visits per capita }=\text { HRWK } \times \text { OPSY)K } / \\
\text { POP, where } K=\text { Aggregate visits/hours } \\
\text { ratio }\end{array}$ & AMA \\
\hline PLVIS & In (PVISIT) & \\
\hline PAGE & Psychiatrist mean age in years & APA \\
\hline AGSQ & Psychiatrist mean age squared & \\
\hline OUT5 & $\begin{array}{l}1 \text { if the State has mandated out- } \\
\text { patient insurance benefits for } \\
\text { treatment of mental disorders of } \\
\text { at least } \$ 500 \text {, } 0 \text { othervise }\end{array}$ & GLS Associates \\
\hline PBED & $\begin{array}{l}\text { Number psychiatric beds per } \\
\text { capita }\end{array}$ & $\begin{array}{l}\text { American Hospital } \\
\text { Association (AHA) }\end{array}$ \\
\hline MDPOP & $\begin{array}{l}\text { Number non-psychiatrist } \\
\text { physicians per } 1000 \text { population }\end{array}$ & AMA \\
\hline LINS & $\begin{array}{l}\text { In (real health insurance ben- } \\
\text { efits paid per capita) health } \\
\text { insurance benefits are measured }\end{array}$ & $\begin{array}{l}\text { Health Insurance } \\
\text { Association of } \\
\text { America (HIAA) }\end{array}$ \\
\hline
\end{tabular}


by the total value of payments

for services covered by health

insurance policies in each state

RYP

In (real per capita income of the population of a state)

$S A B$

PCWHT Percent of population that is white (white pop/POP)

PCAG Percent of population over 18

$S A B$

years of age

PCHS Percent of population having

$S A B$

finished high school $\times 10$

PCGOV

Portion of workforce employed

by government. Government

$S A B$

employees/total employed

PCMAN

Portion of workforce employed

$S A B$

by manufacturing. Manufacturing

employees/total employed

PSKXP

In (real public school expendi-

tures per capita)

$S A B$

REMB

1 if states have enacted a "Freedom

of choice" law, 0 otherwise

áS Associates

HBEDS

Number general hospital beds

per 1000 population

AHA

PCMT

Percent of a state's population

$S A B$

living in an SMSA $\times 10$

UNEM Percent of labor force unemployed BLS

$\times 10$

PCPL

Applicants passing medical license

examination/total applicants

AMA

NNSP

Number of medical schools

per 1000 population

AMA

LFEE

In (real average fee for 50

minutes of psychotherapy by

HCFA/AMA 
Table 2

Means and Standard Deviations

for Selected Variables

\begin{tabular}{|c|c|c|c|}
\hline Variable & Mean & Variable & Mean \\
\hline & $\left(S . n_{0}\right)$ & PCWT & 86 \\
\hline \multirow[t]{2}{*}{ RFEE } & 4.405 & PCAG & 68 \\
\hline & $(9.06)$ & & (20) \\
\hline \multirow[t]{2}{*}{ PSPOP } & 0.07 & PCHS & 66.8 \\
\hline & $(0.06)$ & & $(8.94)$ \\
\hline \multirow[t]{2}{*}{ PAGE } & 46.70 & PCGOV & 20.39 \\
\hline & $(5.01)$ & & $(5.91)$ \\
\hline \multirow[t]{2}{*}{ HRWK } & 47.33 & & \\
\hline & $(2.63)$ & PCMAN & 21.51 \\
\hline \multirow[t]{2}{*}{ POP } & 4,025 & & $(9.50)$ \\
\hline & $(4,185)$ & HBEDS & 26,457 \\
\hline \multirow[t]{2}{*}{ PBEDS } & $4,967.53$ & & $(27,797)$ \\
\hline & $(6,841.72)$ & PCMT & 57.01 \\
\hline \multirow[t]{2}{*}{ RGP } & .979 & & $(27.46)$ \\
\hline & $(1.74)$ & UNEM & 5.71 \\
\hline \multirow[t]{2}{*}{ RPIN } & 1.251 & & $(1.74)$ \\
\hline & $(2.61)$ & PSCXP & 300 \\
\hline \multirow[t]{2}{*}{ INSUR } & 168.50 & & $(100)$ \\
\hline & $(59.50)$ & PCVIS & 0.00373 \\
\hline \multirow[t]{2}{*}{ RYP } & 7,000 & & $(0.0056)$ \\
\hline & $(1,000)$ & & \\
\hline
\end{tabular}


导

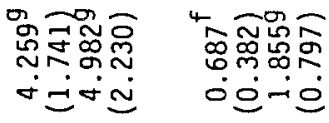

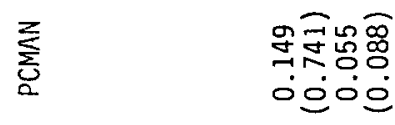

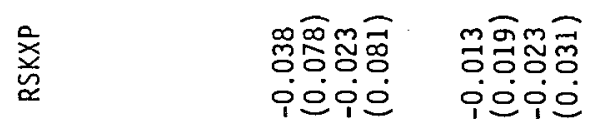

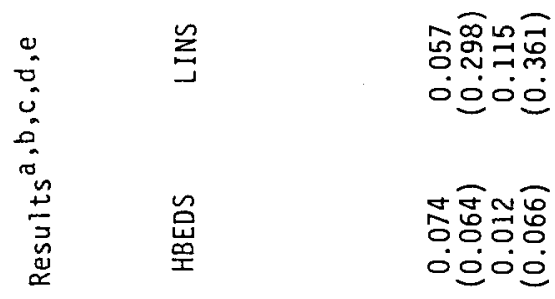

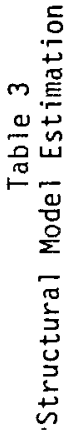

怘

4 ํㅜㅇㅇㅝ

논 용ㅇㅇㅇㅇㅛ.

i용

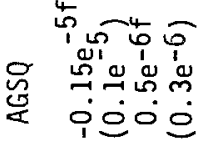

ㄷㅇㅇ융

í0

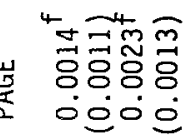

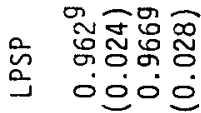

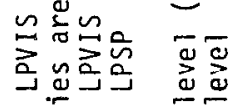

"产"

등.

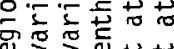

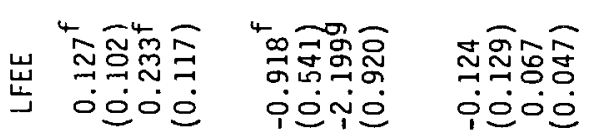

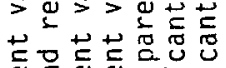

次 듬

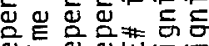

迨汇吉出的的

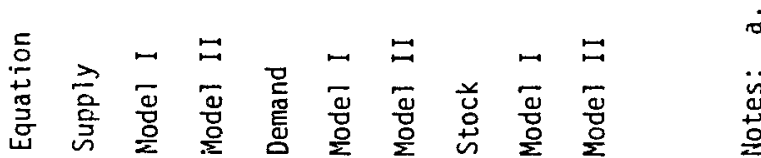




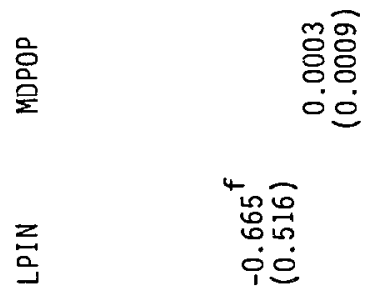

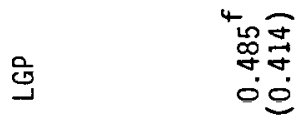

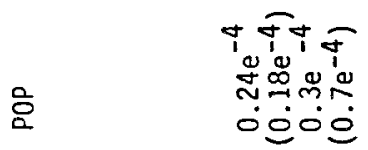

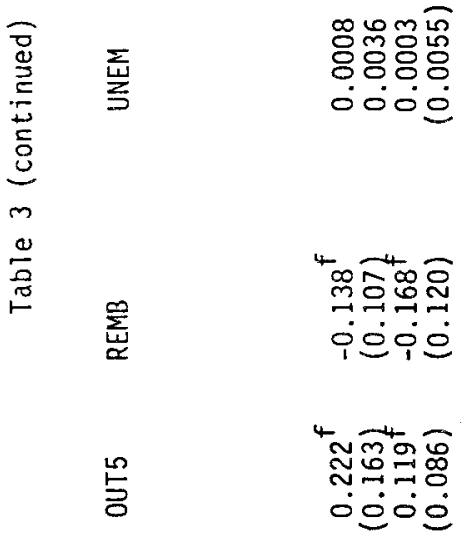

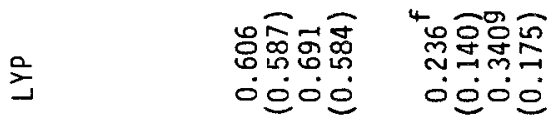

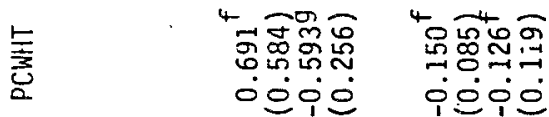

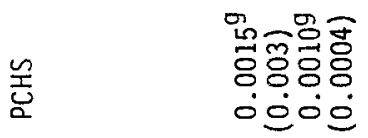

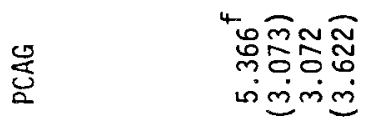

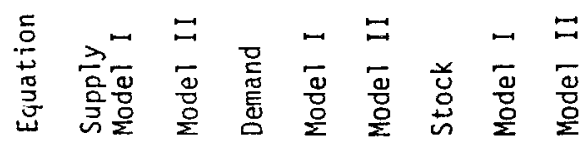


Table 3 (continued)

Equation

PCPL

PCMT

NMSP

LPSPI

Supply

Model I

Model II

Demand

Model I

Model II

Stock

Model I

Model II

$\begin{array}{cc}-0.053 & 0.14 e^{-3 f} \\ (0.064) & \left(0.9^{-4}\right) \\ 0.055 & 0.6^{-3 g} \\ (0.082) & \left(0.1^{-3}\right)\end{array}$

1.640
$(1.539)$
4.6029
$(1.988)$

$0.792^{\mathrm{g}}$

$(0.031)$

0.5989

$(0.036)$ 
Table 4

Location Equation Long Run Coefficients

$\begin{array}{lcc}\text { Variable } & \text { Model I } & \text { Model I I } \\ & (\lambda=.20) & (\lambda=.40) \\ \text { LFEE } & -.0625 & 0.168 \\ \text { LYP } & 1.18 & 0.85 \\ \text { PCPL } & -0.265 & 0.137 \\ \text { PCMT } & 0.0007 & 0.0015 \\ \text { PCGOV } & 3.435 & 4.637 \\ \text { NMSP } & 8.2 & 11.505 \\ \text { RSKXP } & -0.065 & -0.057\end{array}$




\section{REFERENCES}

Benham, L., Maurizi, A. and Reder, M.W., "Location and Migration Medics: Physicians and Dentists," Review of Economics and Statistics, August $1968,50,332-347$.

Dyckman, Zachary Y., A Study of Physicians' Fees, Staff report prepared by the Council of Wage and Price Stability, Executive Office of the President, Washington, D.C.; March 1978.

Evans, Robert G., Price Formation in the Market for Physicians' Services in Canada, 1957-1969. Study prepared for the Prices and Incomes Commission, Canada, 1972. Information Canada, Ottawa, Canada 1973.

Evans, Robert G., "Supplier-Induced Demand: Some Empirical Evidence and Implications," in The Economics of Health and Medical Care, ed., M. Perlman, John Wiley and Sons, New York, 1974, 164-173.

Feldstein, Martin S., "The Rising Price of Physicians' Services," The Review of Economics and Statistics, May 1970, 11, 121-133.

Frank, R.G. Pricing and Location of Physician Services in Mental Health, unpublished Ph.D. Dissertation, Boston University, 1981.

Fuchs, V.R., "The Supply of Surgeons and the Demand for Operations," Journal of Human Resources, 1978 Supplement, 13, 35-55.

Fuchs, Victor R. and Kramer, Marcia J., Determinants of Expenditures for Physicians' Services in the United States, National Center for Health Services Research and Development. Washington, D.C., 1972.

Griliches, Z., "Disturbed Lags: A Survey," Econometrica January 1967, 35, p. 16-49. 
Johnston, J., Econometric Methods, McGraw Hi11, Inc., New York, 1972. Leibenstein, H., "Bandwagon, Snob and Veblen Effects in the Theory of Consumer Demand," Quarterly Journal of Economics, May 1950, 64 (2), 183-207. McGuire, T.G. and Montgomery, J.T., "Mandated Mental Health Benefits in Private Health Insurance Policies: A Legal and Economic Analysis, Journal of Health Politics Policy and Law, 1982, 7 (2), 380-406.

McGuire, Thomas G., "Markets for Psychotherapy," in Psychotherapy: Practice, Research, Policy, ed., G. Vandenbos, Sage Publishing, Beverly Hills, CA, 1980 .

McGuire, Thomas G., Financing Psychotherapy: Costs Effects and Public

Policy, Ballinger; Cambridge, 1981.

Mundlak, Y., "On the Pooling of Time Series and Cross Section Data," Econometrica, January 1978, 46, 69-85.

Musgrave, G.L., "A Market Model of the Distribution of Dentists," in The Target Income Hypothes is, DHEW, HRA 80-27, 1980, 60-82.

National Center for Health Statistics, "The National Ambulatory Medical Care

Survey: 1977 Summary," Vital and Health Statistics. Series 13 No. 44, April 1980.

Newhouse, J.P. "A Model of Physician Pricing," Southern Economic Journal (October 1970) 174-183.

Newhouse, J.P. and Phelps, C.E., "New Estimates of Price and Income Elasticities of Medical Care Services," in The Role of Health Insurance in the Health Services Sector, ed., R.N. Rosett, National Bureau of Economic Research, New York, 1976. 261-313. Newhouse, J.P., Phelps, C.E. and Marquis, M.S., "On Having Your Cake and Eating It Too: Econometric Problems in Estimating the Demand for Health Services," Journal of Econometrics, $1980,13,365-390$. 
Pauly, M.V. and Satterthwaite, M.A. "The Effects of Provider Supply on Price," in The Target Income Hypothesis, DHEW, HRA 80-27, 1980, 26-35.

Reed, L.S., Meyer, E.S. and Scheidemandel, P.D., Health Insurance and Psychiatric Care: Utilitation and Cost, American Psychiatric Association, Washington, 1972.

Reed, L.S., Coverage and Utilization of Care for Mental Conditions Under Health Insurance - Various Studies 1973-1974, American Psychiatric Association, Washington, 1975.

Reinhardt, U.E., "Comment on Monopolistic Elements in the Market for Physician Services," in Competition in the Health Care Sector, ed., W. Greenberg, Aspen Publications, Germantown, 1978, 121-148.

Sloan, F.A., "Physician Fee Inflation: Evidence from the late 1960's," in The Role of Health Insurance in the Health Services Sector, ed., R. N. Rossett, National Bureau of Economic Research, New York City, 1976 , $321-354$

Sloan, F.A. and Feldman, R., "Competition Among Physicians" in Competition in the Health Care Sector, ed., W. Greenberg, Aspen Publications, Germantown, $1978,45-102$.

Steinwald, Bruce and Sloan, Frank A., "Determinants of Physicians' Fee," Journal of Business, October 1974, _, 493-511.

Trevelyan, J. and Eastwood, M.R., "The Relationship Between Physical and Psychiatric Disorder," Psychological Medicine, 1972, 2, 363-372.

U.S. Supreme Court, Blue Shield of Virginia vs. Virginia Academy of Clinical Psychologists, No. $80-930$.

U.S. Court of Appeals 4th District, Virginia Academy of Clinical Psychologists vs. Blue Shield of Virginia, No. 29-1345. 